\title{
In vitro screening of gamma irradiated rice variety MR263 for drought tolerance using polyethylene glycol
}

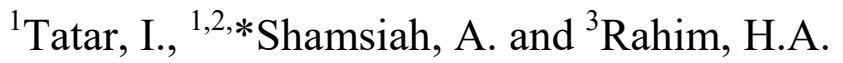

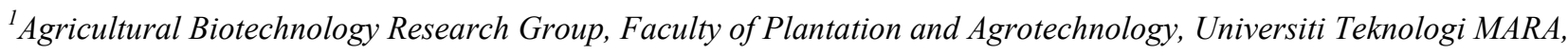 \\ 40150 Shah Alam, Selangor \\ ${ }^{2}$ Faculty of Plantation and Agrotechnology, UiTM Cawangan Melaka Kampus Jasin, 77300 Merlimau, Melaka \\ ${ }^{3}$ Research Agrotechnology and Biociences Division, Malaysian Nuclear Agency, 43000 Kajang, Selangor, Malaysia
}

\author{
Article history: \\ Received: 22 July 2020 \\ Received in revised form: 3 \\ December 2020 \\ Accepted: 10 December 2020 \\ Available Online: 20 \\ December 2020
}

\section{Keywords:}

Oryza sativa,

Rice,

Gamma irradiation,

Drought tolerant,

Gamma-ray

\section{DOI:}

https://doi.org/10.26656/fr.2017.4(S5).008

\begin{abstract}
Fluctuating weather conditions and climate change are affecting agricultural production worldwide including rice yield. Combined with the increasing population and decreasing land space for agricultural practices, biotechnological solutions are needed to improve the livelihood of farmers and the country's food security. Rice seeds of $c v$. MR263 were irradiated with gamma rays at doses 300,350 , and 400 Gy to evaluate their response to ionizing radiation on their growth. The irradiated seeds were germinated on MS media, and the seedlings were grown in media with polyethylene glycol 6000. It was found that most of the germination percentage decreased gradually with increasing radiation dosage. Shoot lengths reduced with radiation dose, per treatment. The root length was highest at dose $350 \mathrm{~Gy}(9.5 \mathrm{~cm})$ compared to the other irradiated treatments. Fresh and dry weights generally decreased with increasing dosage and water stress levels except for dose 350 Gy. The highest fresh $(354 \mathrm{mg})$ and dry weight $(56.7 \mathrm{mg})$ were observed in seedlings irradiated with a dose of 350 Gy treated with $0 \%$ PEG and 10\% PEG respectively. The content of proline and carbohydrates increased as the radiation doses and PEG concentrations increased where the highest proline $(11.8 \mu \mathrm{M} / \mathrm{g})$ was observed in $350 \mathrm{~Gy}+$ $20 \%$ PEG. While the highest carbohydrate content $(9.3 \mathrm{mg} / \mathrm{g})$ was observed in $400 \mathrm{~Gy}+$ $20 \%$ PEG. It was concluded that seedlings radiated with 350 Gy showed promising results indicating tolerance to drought stress, due to their improved morphological and biochemical traits.
\end{abstract}

\section{Introduction}

Rice (Oryza sativa L.) is a cereal grain most consumed as a staple food by many human populaces, most prominently in Asian countries. In the year $2018 / 19$, rice was the third-highest grain produced worldwide at an amount of 495.87 million metric tonnes (Shahbandeh, 2019). It is regarded as the most essential grain in terms of its immense nutritional benefits and caloric intake for more than one-fifth of the world's population. One of the major limiting factors for agricultural production in dry and semi-dry areas is water (Hellal et al., 2018). Thus, the lack of suitable amounts of water in these areas causes drought. Drought is especially prominent in South and Southeast Asia, and it is the prime abiotic stress that restricts rice production worldwide (Swapna and Shylaraj, 2017). Perpetual photosynthetic light reactions at the time of drought stress while the intercellular concentration of $\mathrm{CO}_{2}$ is limited leads to the build-up of reduced photosynthetic electron transport elements, in turn lowering the amount of molecular oxygen, leading to the formation of ROS (Basu et al., 2016).

Rice variety MR263 is a lowland, high-yielding rice, and it matures approximately 97 to 104 days after seeding. During the coming years, there is a high possibility that water will be limited, and with the ongoing climate change effects, farmers may face a problem with irrigation, thus leading to increased chances of crop low yield (Sen et al., 2017). Therefore, effective techniques must be developed to improve crop productivity in areas with water deficiency. Recently, tissue culture procedures were established to be a possible cost-effective technique in improving stress tolerance in plants (Kadhimi et al., 2016). Compared to tissue culture, conventional breeding methods are cost and worker-intensive, as well as time-consuming. To 
study the effects of drought stress that is encountered during the growth stages of plants, pure water potential in the soil environment must be created and maintained. Therefore, it is preferable to use polyethylene glycol (PEG) that has a high molecular weight as an osmoticum, as it is not taken up by the plants, and it is used to adjust osmotic potential in germination studies (Hellal et al., 2018).

Mutations can change traits and functions of genes that code for plant development, and to generate alterations that lead to better genetic development and economic yield (Usharani and Kumar, 2015; Kamaruddin and Abdullah, 2017). Mutation breeding has been introduced to alter one or two major characters of crops to transform them into crops that are resilient to stress. The use of gamma irradiation to induce mutation helps farmers in accessing and monitoring characteristics of crops that are targeted for improvement (JankowiczCieslak et al., 2017). According to the IAEA, more than four hundred rice varieties are being produced around the world using this method (Li et al., 2016). In this study, MR263 seeds were exposed to three doses of gamma radiation $(300,350$, and $400 \mathrm{~Gy})$ and were germinated under water deficit conditions using PEG 6000 solutions of different concentrations (w/v) $(0,10$, and 20\%) in vitro to determine the survival rate and analyse the morphological changes in the seedlings.

\section{Materials and methods}

\subsection{Gamma radiation treatment}

The seeds MR263 were provided by the seedbank of the Malaysian Agricultural Research and Development Institute (MARDI), Penang, Malaysia. The seeds were exposed to three doses $(300,350$ and $400 \mathrm{~Gy})$ of gamma irradiation (Caesium - 137) with a dose rate of $11.8 \mathrm{~Gy} /$ min at a strength of 131 Tera Becquerel (TBq), at the Malaysian Nuclear Agency, Bangi, Selangor, Malaysia.

\subsection{Seed Germination and water stress treatment}

The rice seeds were sterilized using Benomyl, Clorox, and Tween 20, and ethanol, all for a duration of 1 minute each. First, a solution consisting of $0.2 \%$ of Benomyl was used to wash the seeds for 1 minute, afterwards, the seeds were washed in $70 \%$ Clorox and three drops of Tween 20, followed by sterilizing with 50, $40,30,20$, and $10 \%$ Clorox, and lastly with $70 \%$ ethanol. Finally, the seeds were rinsed with sterile distilled water four times to get rid of any remaining sterilizing solutions (Nor Yasmin et al., 2016). The seeds were transferred to Petri dishes containing MS media (3-4 seeds per petri dish). The seeds were left to germinate for 7 days inside an incubation chamber at $25 \pm 2{ }^{\circ} \mathrm{C}$, with a light/dark photoperiod of 16/8 hrs (Kadhimi et al., 2016).

Water deficit was initiated using PEG 6000. Concentrations 10 and 20\% (w/v) of PEG were prepared and sterilized using a $0.22 \mu \mathrm{m}$ filter and poured as overlay solutions on top of solidified half-strength MS media inside glass vials, left overnight, then decanted. Seven days after germination, the seedlings were transferred to the vials at concentrations 0,10 , and $20 \%$ PEG for water stress induction. All cultures were kept at $25 \pm 2^{\circ} \mathrm{C}$ in a $16 / 8 \mathrm{hrs}$ (light/dark) photoperiod.

\subsection{Biochemical analysis}

\subsubsection{Proline concentration in the seedling}

The concentration of proline was determined according to the method by Bates et al. (1973). The seedlings were evaluated for proline content 10 days after the water stress treatments by PEG. The ninhydrin reagent was prepared by warming $1.25 \mathrm{~g}$ of ninhydrin along with $20 \mathrm{~mL} 6 \mathrm{M}$ orthophosphoric acid and $30 \mathrm{~mL}$ glacial acetic acid, with continuous stirring until dissolved. Plant samples of $0.5 \mathrm{~g}$ from the 12 treatments were homogenized along with $10 \mathrm{~mL}$ of $3 \%$ sulfosalicylic acid using a mortar and pestle, and the homogenate was centrifuged at $11,000 \mathrm{rpm}$ for $15 \mathrm{~min}$. A volume of $2 \mathrm{~mL}$ of supernatant was transferred to test tubes and stirred with $2 \mathrm{~mL}$ glacial acetic acid and $2 \mathrm{~mL}$ ninhydrin reagent and incubated at $100^{\circ} \mathrm{C}$ for $1 \mathrm{hr}$ in a water bath. The samples were then cooled in ice for 15 mins and left at room temperature for 5 mins. Lastly, the samples were vigorously mixed with $4 \mathrm{~mL}$ toluene using a vortex for 20 secs, then $3 \mathrm{~mL}$ was pipetted into glass cuvettes and the absorbance of the samples was measured at $520 \mathrm{~nm}$ using a spectrophotometer (UV/ VIS). A blank solution was made alongside the sample solutions using distilled water and the same amounts of the reagents mentioned above. A standard curve was constructed, and the proline concentration was expressed as micromolar per gram fresh weight, using the following equation (Bates et al., 1973):

Proline $(\mu \mathrm{M} / \mathrm{g})=[(\mu \mathrm{g}$ proline $/ \mathrm{mL} \times \mathrm{mL}$ toluene $) / 115.5$ $\mu \mathrm{g} / \mu \mathrm{mole}] /[(\mathrm{g}$ sample $) / 5]$

\subsubsection{Carbohydrates concentration in the seedlings}

The method of phenol sulfuric acid (Herbert et al., 1971) was used to determine the total sugar content (carbohydrates concentrations), without the identification of specific sugar components. The seedlings were evaluated for carbohydrates content 10 days after the PEG treatments. The seedlings were dried at $70^{\circ} \mathrm{C}$ for 48 hrs and $10 \mathrm{mg}$ of the dried plant samples were homogenized with $2 \mathrm{~mL}$ distilled water using a mortar and pestle. The extract was filtered using a Whatman \#1 
filter paper, and to $1 \mathrm{~mL}$ of the filtrate, $1 \mathrm{~mL}$ of $5 \%$ phenol, and $5 \mathrm{~mL}$ of $98 \%$ sulphuric acid were added. The reaction mixtures were vortexed for 20 secs. Then, the samples were incubated at $30^{\circ} \mathrm{C}$ for $20 \mathrm{~min}$ in a water bath then placed in ice to stop the reaction, and $2 \mathrm{~mL}$ was pipetted into disposable plastic cuvettes, and their absorbance was measured at $485 \mathrm{~nm}$ using a spectrophotometer (UV/VIS). A blank solution was made alongside the sample solutions using distilled water and the same amounts of the reagents mentioned above. The carbohydrate concentration was calculated from the standard curve and expressed as milligram per gram dry weight.

\subsection{Data collection parameters}

Germination percentage (GP) of the seedlings after treatment with gamma radiation and seedling survival (SS) percentage after treatment with both gamma radiation and PEG were measured using the following equations (Olasupo et al., 2016). The germination index (GI) was calculated using the following equation (Association of Official Seed Analysis, 1983). The seed vigour (SV) was calculated as described by Abdul-Baki and Anderson (1970).

GP $(\%)=($ Number of germinated seeds $) /($ Number of irradiated seeds planted) $\times 100$

$\mathrm{GI}=($ Number of germinated seeds / Day of first count $)+$ (Number of germinated seeds / Day of second count) $+\ldots+$ (Number of germinated seeds / Day of final count)

$\mathrm{SV}=[$ Germination percentage $\times$ Means of seedling length (root + shoot)] / 100

The relative water content (RWC) was calculated by following the method described by Zaman et al. (2018). Fresh weights of fully expanded leaves were measured, and then they were soaked in distilled water for $16 \mathrm{hrs}$ at room temperature to obtain turgid weight (TW). After that, the leaves were wiped with tissue paper and the turgid weight was measured, and the leaves were dried in the oven at $80^{\circ} \mathrm{C}$ for $84 \mathrm{hrs}$ to measure their dry weight. The RWC was calculated using the formula provided by Turner (1986):

$$
\mathrm{RWC}(\%)=100 \times[(\mathrm{FW}-\mathrm{DW}) /(\mathrm{TW}-\mathrm{DW})]
$$

\subsection{Seed germination and water stress treatment}

The normality test was conducted on the data before statistical analysis of variance (ANOVA) among the treatments, using Microsoft Excel software. The comparison was made between the gamma radiated and water stress treatment groups, values of $\mathrm{p}<0.05$ were considered significant.

\section{Results and discussion}

\subsection{Effects of gamma radiation}

\subsubsection{Seed germination}

The earliest germination was recorded on the second day after culturing in MS media, which was observed in all seeds but at varying rates. On day 3, the highest Germination Percentage (GP) was at the highest radiation dose of $350 \mathrm{~Gy}(42.8 \pm 10.18 \%)$, and the lowest was in the control seeds $(13.1 \pm 7.07 \%)$. Gamma radiation elevated the ability of the seeds, especially at the dose of $350 \mathrm{~Gy}$, which made them germinate at higher rates than the non-radiated seeds. Until the fourth day of germination (day 5), the gamma radiation efficiency had its maximum positive effects on the GP of seeds exposed to $350 \mathrm{~Gy}$, as shown in Figure 1. After that point, the GP started to decrease. These seeds had a GI of 39 which is higher than seeds treated with doses 300 Gy and $400 \mathrm{~Gy}$, as shown in Table 1. GI is a way of expressing the earliness of emergence of the radicle from a seed, the control seeds had the lowest GI than the other seeds at 25 , while the 400 Gy radiated seeds had a GI of 30 . In terms of germination speed, these findings suggest that gamma radiation at the dose 350 Gy provided mutation in the cells of radiated seeds that contributed to optimum conditions, leading to maximum germination and development into seedlings earlier than the other doses.

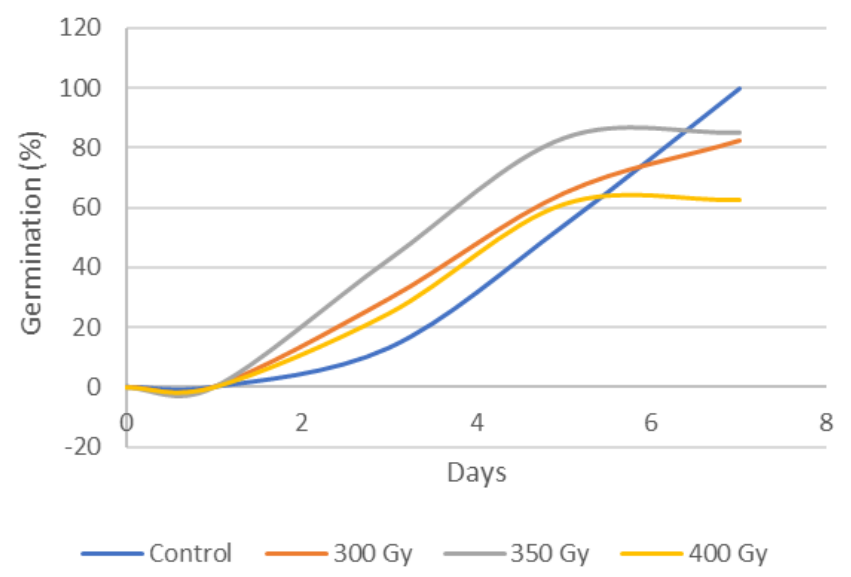

Figure 1. Germination percentage of the irradiated seeds for the duration of one week

Table 1. Germination percentage (GP), germination index (GI), and seed vigour (SV) of the irradiated seeds.

\begin{tabular}{cccc}
\hline & GP $(\%)$ & GI & SV (\%) \\
\hline 0 Gy & 100 & 25 & 34 \\
300 Gy & 82.2 & 34 & 22 \\
350 Gy & 85.3 & 39 & 25 \\
400 Gy & 62.6 & 30 & 13 \\
\hline
\end{tabular}

Lagoda (2012) explained that genetic and physiological damages to embryo cells by mutagenesis are responsible for low germination of seeds, causing mutation, cell death, abnormal cell division, tissue and organ collapse, and reduction of plant growth. Several 
studies (Kadhimi et al., 2016; Gowthami et al., 2017; AlGhaliya and Mukhtar, 2018) reported a decrease in germination percentage of rice seeds with an increase of gamma radiation dosage. The seed vigour was measured using the formula by Abdul-Baki and Anderson (1970), which decreased as the gamma radiation increased (Table 1)

The control seeds had the highest GP and SV, at the values $100 \%$ and $34 \%$ respectively, but the lowest GI at 25. Among the radiated seeds, the dose 350 Gy resulted in the highest SV with a value of $25 \%$, while the seeds radiated with 400 Gy had the lowest SV at $13 \%$. The decrease in vigour is due to the harmful effects of gamma radiation on the cellular division and biological activities of plants, leading to a reduction in their growth and development. Harding et al. (2012) recorded lower vigour in rice as the gamma radiation dose increased, and the same result was observed in cowpea (Olasupo et al., 2016).

\subsubsection{Shoot and root lengths}

As the gamma radiation doses increased, shoot and root lengths gradually decreased. This ionizing radiation had affected the seedlings' development that included the shoots and roots, which were not able to grow to their maximum capacity as compared to the control. At normal water levels ( $0 \%$ PEG), the control seedlings had the longest mean shoot length of $27.5 \pm 2.55 \mathrm{~cm}$ while seedlings pre-radiated with doses $300 \mathrm{~Gy}, 350 \mathrm{~Gy}$, and $400 \mathrm{~Gy}$ had mean shoot lengths of $24.1 \pm 1.44 \mathrm{~cm}$, $24.7 \pm 4.00 \mathrm{~cm}$, and $22.3 \pm 2.02 \mathrm{~cm}$, respectively. The difference in shoot length between the control and the highest gamma radiation (400 Gy) is $5 \mathrm{~cm}$, indicating that the doses used in this study affected the seedling heights in a degrading manner. The statistical analysis, however, revealed that all the shoot lengths were not significantly different $(p<0.05)$. The few centimetre difference in length may be considered negligible and thus it can be concluded that the gamma radiation did not affect the shoot elongation of the plants significantly. The current findings are contradictory to those of Elrefaee et al. (2017) and Abdullah et al. (2018), who observed a significantly different decrease in the shoot lengths of the radiated and non-radiated plants. Likewise, Kim et al. (2015) observed a decrease in the average height of gamma radiated Brachypodium plants. Amsal and Ishak-Ishak (2018) recorded an increase in root length. With roots lacking in length and density, a rice plant is not able to extract and capture the required water, minerals, and nutrients needed for its development and survival.

At normal water levels, the lengths of roots decreased with gamma radiation dose, with an exception seen at 350 Gy (Figure 2). The highest root length was of the control seedlings, with a mean root length of $11.3 \pm 1.35 \mathrm{~cm}$, followed by the seedlings pre-radiated with 350 Gy at $9.5 \pm 2.24 \mathrm{~cm}$, seedlings pre-radiated with $300 \mathrm{~Gy}$ at $7.4 \pm 1.35 \mathrm{~cm}$, and finally, seedlings preradiated with 400 Gy at $6.3 \pm 1.54 \mathrm{~cm}$. Roots play an important role in providing a nutrient and water uptake system necessary for plant growth, act as storage organs, secure plants into the soil, and serve as a means of interaction with pathogenic and beneficial organisms in the rhizosphere (Amsal and Ishak, 2018). Root elongation of rice seedlings decreased as the gamma radiation dose increased (Magnaye et al., 2017; Gowthami et al., 2017). In the present study, roots with noticeably longer length at 350 Gy compared to the other doses might be an indicator of a positive mutation effect on the root growth.

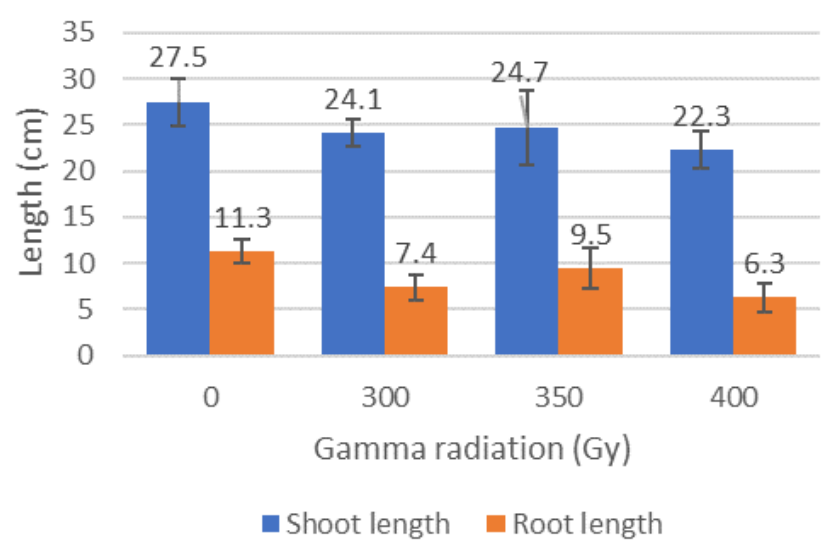

Figure 2. Shoot and root lengths of the seedlings pre-radiated with different gamma radiation doses

\subsection{Effects of drought stress}

\subsubsection{Survival rate of seedlings and relative water} content

All the seedlings survived at the end of the 10 days. This contradictory to the findings of Amsal and IshakIshak (2018), whereby in their study, out of 35 rice mutant lines gamma radiated with doses of 25 and 50 Gy and treated with $20 \%$ PEG, only 22 lines grew well. The characteristics of the positive control and irradiated seedlings grown in MS media and the three PEG treatments are presented in Figures 3, 4, and 5.

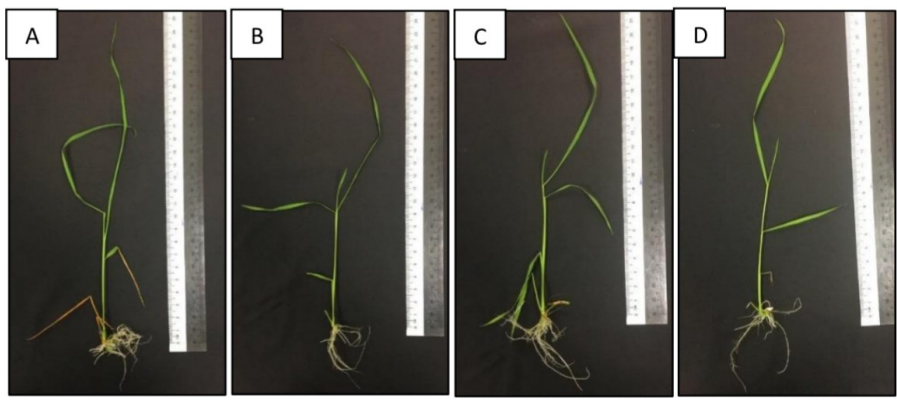

Figure 3. Irradiated MR 263 rice variety 15 days after germination, under different gamma radiation treatments: (A) Control, (B) 300 Gy, (C) 350 Gy, (D) 400 Gy. 


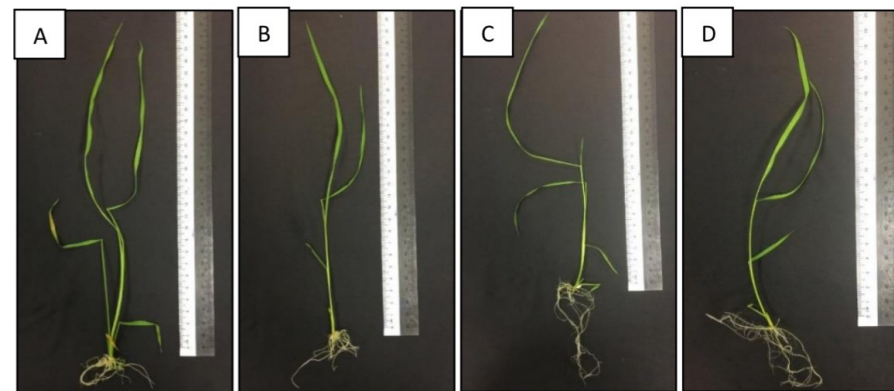

Figure 4. Irradiated MR 263 rice variety 10 days after growth in $10 \%$ PEG, under different gamma radiation treatments: (A) Control, (B) 300 Gy, (C) 350 Gy, (D) 400 Gy.

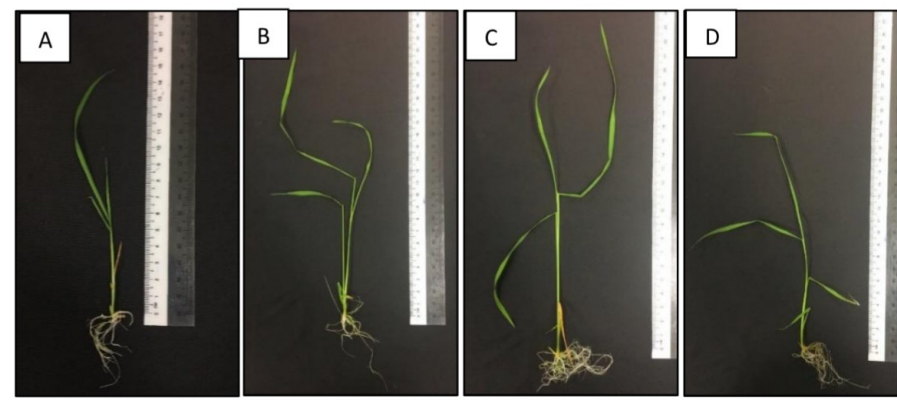

Figure 5. Irradiated MR 263 rice variety 10 days after growth in $20 \%$ PEG, under different gamma radiation treatments: (A) Control, (B) 300 Gy, (C) 350 Gy, (D) 400 Gy.

There was visible chlorosis, curling, and wilting of the leaves, combined with burning of the roots in seedlings belonging to several treatments which can be attributed to the effects of gamma radiation and/or PEG, whereby the seedlings employed protection mechanisms against the damaging effects of these agents by halting their tissues growth and curling their leaves to minimize water loss. Seedlings that were grown in dry conditions possessed leaves and roots that had experienced wilting and turned brown in colour, which may be the effect of drought that leads to the formation of destructive ROS, reduction of photosynthesis and total chlorophyll content in the plant tissues, which is responsible for the green colour of the upper plant tissues (Chutia and Borah, 2012).

It is interesting to note that pre-radiated seedlings exposed to the lowest water stress level of $10 \%$ PEG had fully expanded green leaves and healthy roots, which is not true in the case of the control seedlings. These intact seedlings can be considered for further growth and metabolic studies. A possible explanation is that mutation by gamma radiation can lead to unforeseen advantageous modifications in the structure of certain cell organelles of the seedlings, such as chlorophyll organelles. It was mentioned in previous studies that gamma radiation can cause an increase in photosynthetic pigments like chlorophylls (Beyaz et al., 2016), that capture sunlight photons are converted by the plants into energy compounds by photosynthesis. Soni et al. (2011) reported that at 20\% PEG, plants experienced chlorosis, wilting, and burning of leaves and roots. In rice plants, it was determined that the leaf rolling factor is one of the best traits in assuming levels of water shortage resilience in a screening upon large scale samples (Pandey and Shukla, 2015).

The RWC was used in this study as a measure of drought. This index, as mentioned by Swapna and Shylaraj (2017), is a useful tool to estimate the water status of plants. The results showed that the RWC of the leaves of seedlings decreased slightly with increasing gamma radiation dose since radiation contributes to lowered water potential; and it decreased as the PEG concentration increased. The lowest RWC recorded was of the seedlings 400 Gy with RWC at $44 \%$ at the highest drought stress level. Sarker and Oba (2018) recorded a gradual decrease in relative water content in shoots of seedlings under drought stress. The gamma radiation affected the RWC of mutated MR263 seedlings under drought in a negative way. Especially the PEG concentration, as these two agents play a role in the declination of osmotic potential in the plant's growth media (Table 2).

Table 2. Relative water content of seedlings under different treatments of gamma radiation and PEG.

\begin{tabular}{ccccc}
\hline & \multicolumn{4}{c}{ Relative water content (\%) } \\
\cline { 2 - 5 } & $0 \mathrm{~Gy}$ & $300 \mathrm{~Gy}$ & $350 \mathrm{~Gy}$ & $400 \mathrm{~Gy}$ \\
\hline $0 \%$ PEG & 85 & 68 & 61 & 61 \\
$10 \%$ PEG & 82 & 58 & 53 & 52 \\
$20 \%$ PEG & 78 & 56 & 50 & 44 \\
\hline
\end{tabular}

\subsubsection{Shoot and root lengths}

After growing in MS media with less water content for 10 days, the seedlings' shoot lengths were inversely proportional to the gamma radiation doses and were quite irregular with an increase in PEG concentration, as Table 3 elucidates. Variance analysis of the shoot lengths under the 12 treatments indicated no significant difference $(\mathrm{p}<0.05)$ at $0 \%$ PEG, whereas at $10 \%$, the control seedlings had the highest length, while $300 \mathrm{~Gy}$ and 400 Gy pre-radiated seedlings were not significantly different $(\mathrm{p}<0.05)$ in length and at $350 \mathrm{~Gy}$, the shoot length was the lowest. At 20\% PEG, the control seedlings had the lowest length, and the 350 Gy preradiated seedlings had the highest, but not significantly different $(\mathrm{p}<0.05)$ from the 300 Gy and 400 Gy doses. All the radiation doses produced shoot lengths higher than the control at 20\% PEG. Using the treatment 350 Gy and 20\% PEG, the mean shoot length was $25.7 \pm 3.23$ $\mathrm{cm}$, denoting that this dose is optimal for shoot elongation of rice variety MR 263 under drought using $20 \%$ PEG. This result is supported by Amsal and IshakIshak (2018), who claimed that rice mutant lines which were gamma radiated with doses of 25 Gy and 50 Gy 
Table 3. Shoot and root lengths of seedlings under different treatments of gamma radiation and PEG.

\begin{tabular}{ccccccccc}
\hline & \multicolumn{4}{c}{ Shoot length $(\mathrm{cm})$} & \multicolumn{5}{c}{ Root length $(\mathrm{cm})$} \\
\cline { 2 - 9 } & 0 Gy & $300 \mathrm{~Gy}$ & $350 \mathrm{~Gy}$ & $400 \mathrm{~Gy}$ & $0 \mathrm{~Gy}$ & $300 \mathrm{~Gy}$ & $350 \mathrm{~Gy}$ & $400 \mathrm{~Gy}$ \\
\hline $0 \%$ PEG & $27.53 \pm 2.55$ & $7.4 \pm 1.35$ & $9.48 \pm 2.24$ & $6.28 \pm 1.54$ & $11.3 \pm 1.34$ & $24.1 \pm 1.44$ & $24.75 \pm 4.00$ & $22.25 \pm 2.02$ \\
$10 \%$ PEG & $30.37 \pm 0.51$ & $8.8 \pm 2.51$ & $11 \pm 1.11$ & $9.55 \pm 1.81$ & $10.77 \pm 1.93$ & $26.42 \pm 1.66$ & $21 \pm 0.60$ & $25.93 \pm 2.77$ \\
$20 \%$ PEG & $19.77 \pm 0.70$ & $7.75 \pm 0.90$ & $8.38 \pm 1.84$ & $8.83 \pm 2.31$ & $12.8 \pm 1.05$ & $21.5 \pm 2.66$ & $25.7 \pm 3.23$ & $23.33 \pm 2.12$ \\
\hline
\end{tabular}

Values are expressed as mean \pm standard deviation.

and treated with $20 \%$ PEG and did not have significantly different plant heights compared to the positive control were deemed tolerant to drought stress.

Seedlings with longer roots suggest that the plant can survive in environments scarce in water availability better than those with shorter roots. In this study, the control seedlings' roots increased with increasing PEG concentration, while the radiated seedlings' roots increased in length as drought stress increased from $0 \%$ to $10 \%$ PEG, followed by a decrease as the drought stress increased from $10 \%$ to $20 \%$ PEG (Table 3). The lowered lengths of shoots and roots were due to reduced external osmotic potential at $20 \%$ PEG was due to low water presence in the media which led to slow development of roots that subsequently did not transport enough nutrients to the shoots, thus slowing or halting their growth.

The control seedlings not subjected to water stress had a mean root length of $11.3 \pm 1.34 \mathrm{~cm}$, which is not significantly different $(p<0.05)$ from the length of roots of control seedlings subjected to mild water stress at $10 \%$ PEG $(10.77 \pm 1.93 \mathrm{~cm})$. On the contrary, control seedlings grown in severely water-stressed media by $20 \%$ PEG had an increase in root length at $12.8 \pm 1.05 \mathrm{~cm}$ which was significantly higher than all seedlings' roots, and it shows that the roots of rice variety MR263 at this drought level were successful in applying the mechanism of drought adaptation by extending their roots to extract more water, even though their cells did not experience induced mutated by gamma radiation. The presented fluctuation of root lengths concerning drought levels is in accordance with the recorded root lengths of wheat in a study by Mazandarani and Abdi (2017), which observed higher root lengths at -3 bar than the control, and at -6 bar the root lengths were the shortest.

\subsubsection{Seedlings fresh and dry weights}

The highest fresh weight (FW) measured belongs to the positive control seedlings grown in $0 \%$ PEG with an FW of $474.1 \pm 4.45 \mathrm{mg}$, whereas at $10 \%$ PEG it was $353.3 \pm 3.06 \mathrm{mg}$ and lowest at $20 \%$ PEG with $230 \pm 2.64$ $\mathrm{mg}$ (Figure 6A). When looking at the FW in relation to the PEG concentrations only, it appears that higher PEG concentrations led to lower fresh weights, except in seedlings pre-treated with $400 \mathrm{~Gy}$, which displayed an irregular pattern. The formation of ROS is the significance of gamma radiation which leads to many changes in the plant's physiology including hasting the establishment of an oxidative plan, a build-up of phenolic mixtures, and chlorophyll pigments, hence, influencing the shoot and root lengths and fresh and dry weights (Borzouei et al., 2010). The fresh weight of plants radiated with gamma rays was decreased as compared to the control (Kim et al., 2015).

In terms of $\mathrm{DW}$, the most obvious improvement in DW was seen in 350 Gy pre-radiated seedlings. At normal water levels, their DW was $45 \pm 4.56 \mathrm{mg}$, at $10 \%$ PEG 56.7 $\pm 1.85 \mathrm{mg}$, and at 20\% PEG $31.1 \pm 3.50 \mathrm{mg}$ (Figure 6B). All of the values belonging to the intermediate gamma radiation dose (350 Gy) are higher than the other values at respective water stress levels. Most of the drought-tolerant rice genotypes gathered more dry matter (Meesook et al., 2018), and this statement is agreeable with the results of this study as

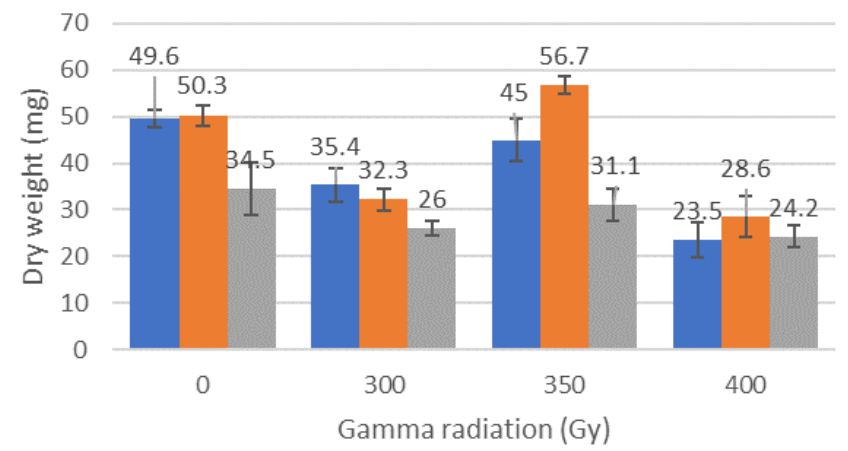

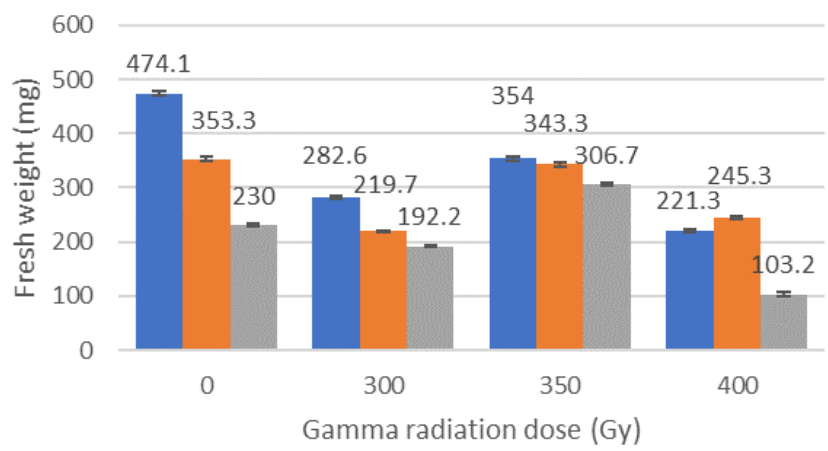

(A)

Figure 6. Fresh weight (A) and dry weight (B) of seedlings treated with different gamma radiation doses and PEG concentrations. 
was shown by the increased DW at $350 \mathrm{~Gy}$. The gamma radiation 400 Gy had the lowest DW, indicating that high doses inhibit the accumulation of DW at normal and low water levels.

\subsection{Effects of water stress on osmolyte content}

\subsubsection{Proline content}

The proline content in the seedlings was found to be generally directly proportional to the level of gamma radiation doses and water stress levels. There was a gradual increase in proline concentrations in all treatments, except for the seedlings pre-radiated with 300 Gy, which underwent some fluctuations in this regard (Figure 7A). The most substantial increase in proline concentration accumulation, across the three levels of water stress, was recorded in seedlings pre-radiated with $350 \mathrm{~Gy}$, whereby it increased by $10 \mu \mathrm{M} / \mathrm{g}$. It was mentioned by Geng et al. (2019) that osmotic adjustment occurs in plants upon gamma radiation and subsequent proline production, which is in line with the results of this study, where the increase in dosage leads to increased levels of proline. Mutation by gamma radiation influenced the production of proline synthesis in the preradiated seedlings upon drought encounter.

Meesok et al. (2018) reported that irradiated rice plants under drought by different concentrations of PEG had higher levels of proline compared to non-irradiated plants. Proline may have a role in avoiding oxidative damage of ROS that accumulate in plants after exposure to different environmental stress (Geng et al., 2019). The seedlings not treated with PEG (control), grown in MS media with normal water content ( $0 \%$ PEG), showed the lowest proline activity with a concentration of $1.3 \pm 0.73$ $\mu \mathrm{M} / \mathrm{g}$, which was expected since these seedlings had neither gamma irradiation exposure nor PEG added to their growth media. However, the proline concentration was boosted in these control seedlings as the levels of drought increased by $10 \%$ and $20 \%$, with values of $2.3 \pm 0.40 \mu \mathrm{M} / \mathrm{g}$ and $8.7 \pm 0.67 \mu \mathrm{M} / \mathrm{g}$, respectively.

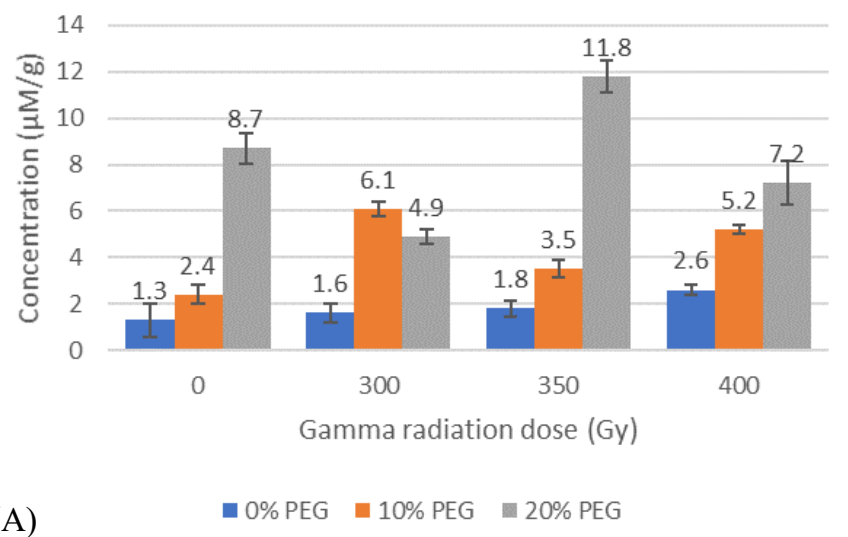

Atabaki et al. (2018) investigated the callus of MR 263 and it was found that the control samples contained proline at a concentration of $0.21 \mu \mathrm{M} / \mathrm{g}$, and upon inducing high levels of salinity stress, the proline content increased. Proline build-up was reported in droughtstressed rice (Swapna and Shylaraj, 2017), and osmanthus seedlings irradiated to high concentrations of salt stress (Geng et al., 2019). In the present work, the highest level of proline synthesized, among all twelve treatments, was in the seedlings pre-radiated at a dose of 350 Gy and grown in water-stressed environment induced by $20 \%$ PEG. These findings are considered to be an indicator of drought tolerance expressed by these seedlings; the high amounts of proline infer that this osmolyte is working to keep the cellular membranes of the plant stable and prevent them from breaking due to lack of water in the tissue.

\subsubsection{Carbohydrates content}

The carbohydrates levels (Figure 7B) were found to be the highest under the treatment of 400 Gy and $20 \%$ PEG $(9.3 \pm 0.76 \mathrm{mg} / \mathrm{g})$ and lowest in control seedlings at $0 \%$ PEG $(5.2 \pm 0.78 \mathrm{mg} / \mathrm{g})$. There was no significant difference $(p<0.05)$ in the carbohydrates contained in the seedlings when they were introduced to mild and severe drought stresses except in control and treatment with $400 \mathrm{~Gy}$. At $300 \mathrm{~Gy}$, it increased from $7.5 \pm 0.74 \mathrm{mg} /$ $\mathrm{g}$ at $0 \%$ PEG to $8.2 \pm 0.58 \mathrm{mg} / \mathrm{g}$ at $20 \%$ PEG. At $350 \mathrm{~Gy}$, it increased by $0.5 \mathrm{mg} / \mathrm{g}$, and lastly, at $400 \mathrm{~Gy}$, it increased by $2.2 \mathrm{mg} / \mathrm{g}$ from $0 \%$ to $20 \%$ PEG. The differences in the values among the two PEG treatments were negligible. The biggest increase in carbohydrates levels was noted in treatment with $400 \mathrm{~Gy}$, followed by the control, $300 \mathrm{~Gy}$, and lowest in $350 \mathrm{~Gy}$. This is due to the high radiation dosage of 400 Gy that leads to the largest accumulation of these sugars among the radiated seedlings. The study by Atabaki et al. (2018) showed that the concentration of soluble sugars in the callus of MR 263 at control conditions was $7.32 \mathrm{mg} / \mathrm{g}$, and it increased as the salinity stress increased.

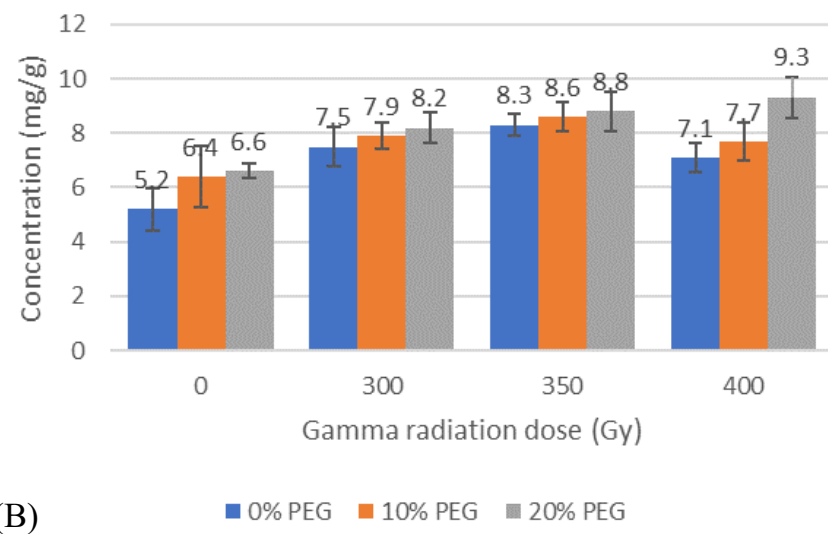

Figure 7. Proline (A) and carbohydrates (B) content of seedlings treated with different gamma radiation doses and PEG concentrations. 
Due to the production of toxic oxygen derivatives by stress, plants have developed a wide range of adaptive techniques to counteract this problem (Hellal et al., 2018). This stress is counteracted in the plants by producing osmolytes to overcome the harmful effects of radiation and drought, such as soluble sugars. Generally, membrane-compatible solutes safeguard the plasma membrane from desiccation-induced damage by ROS (Sarker and Oba, 2018). The solutes include soluble sugars (carbohydrates) and amino acids. Therefore, it can be concluded that there might be a correlation between the ability of osmotic adjustment in plants and the extent of membrane security from the influence of dehydration. Kadhimi et al. (2016) found that rice seedlings had increasing contents of carbohydrates as the gamma radiation and concentration of PEG increased, but they were less than the radiated and non-radiated control. This contradicts the findings of the present study whereby the control had less content of carbohydrates than the preradiated seedlings. Another study by Kumar et al. (2017) reported that the tested oleander plants had slightly increased concentrations of total soluble sugars under drought stress compared to the control. The current results are in agreement with those of Kim et al. (2015) who found that gamma radiation contributed to a slight increase in soluble sugars compared to non-radiated Brachypodium plants.

\section{Conclusion}

Under drought stress condition using PEG 6000, the morphological changes were mostly treatment dependent. While all radiation doses had different alterations in the characteristics of MR263 under drought, it was clear that gamma radiation at dose 350 Gy had the greatest impact compared to the other two doses. The increase in root depth and DW under drought stress has been well established to be a manifestation of drought tolerance. Likewise, the increase of the osmoprotectants proline and carbohydrates in the tissues under water deficiency is a mechanism by the plant to avoid damage by drought. The data recorded in this study highlighted that shoot and root lengths, as well as fresh and dry weights, can be used as a quick selection of seedlings that might have drought-tolerant characteristics. It can be concluded that seedlings that showed better response to drought stress can be used in breeding programmes to improve the survival of rice plants in dry and semi-dry fields and can be cultivated in environments where water availability is constricted.

\section{Conflict of interest}

There are no potential conflicts of interest relevant to this article to be reported.

\section{Acknowledgments}

The authors thank the Ministry of Higher Education Malaysia for the grant FRGS/1/2016/WAB01/ $\mathrm{UPM} / 02 / 13$. The authors also wish to thank the Malaysian Agriculture Research and Development Institute (MARDI) for providing the MR 263 seeds.

\section{References}

Abdul-Baki, A.A. and Anderson, J.D. (1970). Viability and Leaching of Sugars from Germinating Barley. Crop Science, 10(1), 31-34. https://doi.org/10.2135/ cropsci1970.0011183X001000010012x

Abdullah, S., Kamaruddin, N.Y. and Harun, A.R. (2018) The effect of gamma radiation on plant morphological characteristics of Zingiber officinale Roscoe. International Journal on Advanced Science, Engineering and Information Technology, 8(5), 2085 -2091. https://doi.org/10.18517/ijaseit.8.5.4641

Al-Ghaliya, H.K.A.M. and Mukhtar, A.G. (2018). Mutation Induction for Sorghum and Rice Using Gamma and X-Ray Radiations (No. IAEA-CN-263).

Amsal, A. and Ishak-Ishak. (2018). Drought Tolerance and Evaluation of Genetic Changes in Rice Mutant Lines. American Journal of Applied Sciences, 5, 1-9. https://doi.org/10.3844/ajassp.2018.1.9

Association of Official Seed Analysis (AOSA) (1983). Seed Vigor Testing Handbook. Contribution No. 32 to the Handbook on Seed Testing. USA: AOSA.

Atabaki, N., Nulit, R, Kalhori, N., Lasumin, N., Sahebi, M. and Abiri, R. (2018). In vitro Selection and Development of Malaysian Salt-Tolerant Rice (Oryza sativa L. cv. MR263) Under Salinity. Acta Scientific Agriculture, 2(8), 8-17.

Basu, S., Ramegowda, V., Kumar, A. and Pereira, A. (2016). Plant adaptation to drought stress. F1000Research, 5, 1554. https://doi.org/10.12688/ f1000research.7678.1

Bates, L.S., Waldren, R.P. and Teare, I.D. (1973). Rapid determination of free proline for water-stress studies. Plant and Soil, 39(1), 205-207. https:// doi.org/10.1007/BF00018060

Beyaz, R., Kahramanogullari, C.T., Yildiz, C., Darcin, E.S. and Yildiz, M. (2016). The effect of gamma radiation on seed germination and seedling growth of Lathyrus chrysanthus Boiss. under in vitro conditions. Journal of Environmental Radioactivity, 162, 129-133. https://doi.org/10.1016/ j.jenvrad.2016.05.006

Borzouei, A., Kafi, M., Khazaei, H., Naseriyan, B. and Majdabadi, A. (2010). Effects of gamma radiation on 
germination and physiological aspects of wheat (Triticum aestivum L.) seedlings. Pakistan Journal of Botany, 42(4), 2281-2290.

Chutia, J. and Borah, S.P. (2012). Water Stress Effects on Leaf Growth and Chlorophyll Content but Not the Grain Yield in Traditional Rice (Oryza sativa Linn.) Genotypes of Assam, India II. Protein and Proline Status in Seedlings under PEG Induced Water Stress, 3(7), 971-980. https://doi.org/10.4236/ ajps.2012.37115

El-Refaee, Y.Z., Hadifa, A.A. and EL-Shafey, R.A.S. (2017). Induction of Genetic Variability for some Agronomic Traits and Blast Disease Resistance in Egyptian Rice Variety Sakha101. Journal of Plant Production, 8(12), 1373-1381. https:// doi.org/10.21608/jpp.2017.42011

Geng, X., Zhang, Y., Wang, L. and Yang, X. (2019). Pretreatment with High-Dose Gamma Irradiation on Seeds Enhances the Tolerance of Sweet Osmanthus Seedlings to Salinity Stress. Forests, 10(5), 406. https://doi.org/10.3390/f10050406

Gowthami, R., Vanniarajan, C., Souframanien, J. and Pillai, M.A. (2017). Comparison of radiosensitivity of two rice (Oryza sativa L.) varieties to gamma rays and electron beam in M1 generation. Electronic Journal of Plant Breeding, 8(3), 732-741. https:// doi.org/10.5958/0975-928X.2017.00111.9

Harding, S.S., Johnson, S.D., Taylor, D.R., Dixon, C.A. and Turay, M.Y. (2012). Effect of gamma rays on seed germination, seedling height, survival percentage and tiller production in some rice varieties cultivated in Sierra Leone. Journal of Experimental Agriculture International, 247-255. https://doi.org/10.9734/AJEA/2012/820

Hellal, F.A., El-shabrawi, H.M., El-hady, M.A., Khatab, I.A., El-sayed, S.A.A. and Abdelly, C. (2018). Influence of PEG induced drought stress on molecular and biochemical constituents and seedling growth of Egyptian barley cultivars. Journal of Genetic Engineering and Biotechnology, 16(1), 203212. https://doi.org/10.1016/j.jgeb.2017.10.009

Herbert, D., Phipps, P.J. and Strange, R.E. (1971). Chapter III chemical analysis of microbial cells Vol. 5. In Methods in microbiology, p. 209-344. Academic Press. https://doi.org/10.1016/S0580-9517 (08)70641-X

Jankowicz-Cieslak, J., Mba, C. and Till, B.J. (2017). Mutagenesis for Crop Breeding and Functional Genomics. In Jankowicz-Cieslak, J., Tai, T., Kumlehn, J. and Till, B.J. (Eds.) Biotechnologies for Plant Mutation Breeding. p. 3-18. Cham, The Netherlands: Springer
Kadhimi, A.A., Radziah, C., Mohd, C. and Alhasnawi, A.N. (2016). Effect of Irradiation and Polyethylene Glycol on Drought Tolerance of MR269 Genotype Rice (Oryza sativa L.) Asian Journal of Crop Science, 8(2), 52-59. https://doi.org/10.3923/ ajcs.2016.52.59

Kamaruddin N.Y. and Abdullah, S. (2017). Assessment on the Genetic Variability and Fiber Composition of Gamma Ray induced Mutant Lines of Ginger (Zingiber officinale Roscoe). Pertanika Journal of Science and Technology, 25(S), 325-334.

Kim, D.Y., Hong, M.J., Park, C.S. and Seo, Y.W. (2015). The effects of chronic radiation of gamma ray on protein expression and oxidative stress in Brachypodium distachyon. International Journal of Radiation Biology, 91(5), 407-419. https:// doi.org/10.3109/09553002.2015.1012307

Kumar, D., Al Hassan, M., Naranjo, M.A., Agrawal, V., Boscaiu, M. and Vicente, O. (2017). Effects of salinity and drought on growth, ionic relations, compatible solutes and activation of antioxidant systems in oleander (Nerium oleander L.). Plos One, 12(9), e0185017. https://doi.org/10.1371/ journal.pone. 0185017

Lagoda, P.J.L. (2012). Effects of radiation on living cells and plants. In Shu, Q.Y., Forster, B.P. and Nakagawa, H. (Eds.) Plant Mutation Breeding and Biotechnology, p. 123-134. CABI e-books. lhttps:// doi.org/10.1079/9781780640853.0123

Li, S., Zheng, Y.C., Cui, H.R., Fu, H.W., Shu, Q.Y. and Huang, J.Z. (2016). Frequency and type of inheritable mutations induced by $\gamma$ rays in rice as revealed by whole genome sequencing. Journal of Zhejiang University-SCIENCE B, 17(12), 905-915.

Magnaye, A.M.A., Malabanan-Bauan, K.B., Lalican, D.J. and Borromeo, T.H. (2017). Identification of LD50 in selected Philippine traditional rice varieties exposed to gamma radiation. Philippine Journal of Crop Science, 42(1), 107-108.

Mazandarani, M.T. and Abdi, H. (2017). Study of the Tolerance to Drought Stress Levels of (PEG 6000) in Different Genotypes of Wheat Germination Stage. International Journal of Life-Sciences Scientific Research, 3(1), 760-765. https://doi.org/10.21276/ ijlssr.2017.3.1.2

Meesook, K., Pongtongkam, P. and Poeaim, A. (2018). Influences of gamma ray and polyethylene glycol to identify the drought-resistant in the rice (Oryza sativa L. cv. Riceberry) by plant tissue culture. International Journal of Agricultural Technology, 14 (7 Special Issue), 1433-1444.

Nor Yasmin, N.Y., Norrizah, J.S. and Azani, S. (2016). 
Effects of different plant growth hormones on in vitro regeneration of a new Malaysian rice variety (Oryza sativa L. Var. MRIA 1. L. Var. MRIA 1) from stem explants. Journal of Advances in Technology and Engineering Research, 2(4), 125133. https://doi.org/10.20474/jater-2.4.4

Olasupo, F.O., Ilori, C.O., Forster, B.P. and Bado, S. (2016). Mutagenic Effects of Gamma Radiation on Eight Accessions of Cowpea (Vigna unguiculata [L.] Walp.). American Journal of Plant Sciences, 7(2), 339-351. https://doi.org/10.4236/ajps.2016.72034

Pandey, V. and Shukla, A. (2015). Acclimation and tolerance strategies of rice under drought stress. Rice Science, 22(4), 147-161. https://doi.org/10.1016/ j.rsci.2015.04.001

Sarker, U. and Oba, S. (2018). Drought stress effects on growth, ROS markers, compatible solutes, phenolics, flavonoids, and antioxidant activity in Amaranthus tricolor. Applied Biochemistry and Biotechnology, 186(4), 999-1016. https://doi.org/10.1007/s12010018-2784-5

Sen, A., Ozturk, I., Yaycili, O. and Alikamanoglu, S. (2017). Drought tolerance in irradiated wheat mutants studied by genetic and biochemical markers. Journal of Plant Growth Regulation, 36(3), 669-679.

Shahbandeh. (2019). Worldwide production of grain in 2018/19. Retrieved from https://www.statista.com/ statistics/263977/world-grain-production-by-type/

Soni, P., Rizwan, M., Bhatt, K.V, Mohapatra, T. and Singh, G. (2011). In-vitro response of Vigna aconitifolia to drought stress induced by PEG 6000. Journal of Stress Physiology and Biochemistry, 7(3), 108-121.

Swapna, S. and Shylaraj, K.S. (2017). Screening for osmotic stress responses in Rice varieties under drought condition. Rice Science, 24(5), 253-263. https://doi.org/10.1016/j.rsci.2017.04.004

Turner, N.C. (1986). Adaptation to water deficits: a changing perspective. Functional Plant Biology, 13 (1), 175-190. https://doi.org/10.1071/PP9860175

Usharani, K.S. and Kumar, C.A. (2015). Induced polygenic variability using combination treatment of gamma rays and ethyl methane sulphonate in blackgram (Vigna mungo (L.) Hepper). African Journal of Biotechnology, 14(20), 1702-1709. https://doi.org/10.5897/AJB2015.14438

Zaman, N.K., Abdullah, M.Y., Othman, S. and Zaman, N.K. (2018). Growth and physiological performance of aerobic and lowland rice as affected by water stress at selected growth stages. Rice Science, 25(2), 8-9. https://doi.org/10.1016/j.rsci.2018.02.001 